\title{
Multidimensional dynamics of the proteome in the neurodegenerative and ageing mammalian brain
}

\author{
Authors \\ Byron Andrews ${ }^{1,2}$, Sarah Maslen ${ }^{1}$, Leonardo Almeida-Souza ${ }^{1}, J_{\text {Mark Skehel }}{ }^{1}$, \\ René Frank ${ }^{1,3^{*}}$
}

\section{Affiliations}

${ }^{1}$ MRC Laboratory of Molecular Biology, Francis Crick Avenue, Cambridge, CB2 $0 \mathrm{QH}$, United Kingdom

${ }^{2}$ Current Address: Storm Therapeutics, Babraham Research Campus, Cambridge CB22 3AT, United Kingdom

${ }^{3}$ School of Biomedical Sciences, Faculty of Biological Sciences, University of Leeds, LS2 9JT

*Corresponding Author: rene@mrc-Imb.cam.ac.uk

\section{Abstract}

The amount of any given protein in the brain is determined by the rates of its synthesis and destruction, which are regulated by different cellular mechanisms. Here, we combine metabolic labelling in live mice with global proteomic profiling to simultaneously quantify both the flux and amount of proteins in mouse models of neurodegeneration. In multiple models, protein turnover increases were associated with increasing pathology. This method distinguishes changes in protein expression mediated by synthesis from those mediated by degradation. In the $A p p^{N L-F}$ knockin mouse model of Alzheimer's disease increased turnover resulted from imbalances in both synthesis and degradation, converging on proteins associated with synaptic vesicle recycling (Dnm1, Cltc, Rims1) and mitochondria (Fis1, Ndufv1). In contrast to disease models, ageing in wildtype mice caused a widespread decrease in protein recycling associated with a 
decrease in autophagic flux. This simple multidimensional approach enables the comprehensive mapping of proteome dynamics and identifies affected proteins in mouse models of disease and other live animal test settings.

\section{INTRODUCTION}

In the mammalian brain, the rate of protein turnover ranges from minutes to several days (Dwyer et al., 1980; Price et al., 2010b; Savas et al., 2012; Toyama et al., 2013). This extraordinary flux poses a particular challenge for the brain because information must outlive the molecular substrates in which they are stored (Crick, 1984; Lisman et al., 2012). In the adult brain almost all neurons are post-mitotic, thus turnover and repair mechanisms are not helped by replication during cell division, as applies in many other tissues. The rate of proteome turnover is regulated by multiple factors and mechanisms, including ubiquitinproteasome and autophagy-mediated degradation (Goldberg, 2003; Ohsumi, 2006; Vilchez et al., 2014). Protein turnover perturbations cause severe neurological dysfunction (Harris and Rubinsztein, 2011). Indeed, the most common neurodegenerative diseases are characterized by imbalances in the turnover of a few proteins, resulting in their accumulation into mis-folded protein aggregates (Eisenberg and Jucker, 2012; Goedert, 2015). These inclusions appear to be resistant to cellular mechanisms of repair (Ye et al., 2015). Abnormal inclusions in non-neuronal cell culture have been shown to have widespread impact on the proteome and its functions (Kim et al., 2016; Olzscha et al., 2011; Woerner et al., 2016). However, it is not known if neurodegenerative diseases have an impact on global proteome turnover in the mammalian brain.

Neurodegenerative diseases are characterized by synapse loss, cognitive decline, and eventual neuronal death. What triggers these diseases is unknown, except for a very small subset that are caused by familial mutations (Guerreiro and Hardy, 2014; Yancopoulou and Spillantini, 2003). Yet, even in these rare cases, a comprehensive understanding of what downstream pathological pathways are 
involved in cognitive decline, synapse and neuronal loss is lacking (De Strooper and Karran, 2016).

In most neurodegenerative diseases, including Alzheimer's disease (AD), it is apparent that pathology arises over many years, perhaps decades $(\mathrm{H}$. Braak and E. Braak, 1991; Dubois et al., 2016; Goedert, 2015). Consequently, pathology in the early stages of the disease could be masked by increased repair and adaptation (Hardy et al., 2014; Masters and Selkoe, 2012; Musiek and Holtzman, 2015; Zetterberg and Mattsson, 2014). Therefore, methods capable of detecting these changes in repair could indicate the earliest upstream pathways of the disease (De Strooper and Karran, 2016).

To study AD, mouse models provide an excellent setting because genetic approaches can be applied within an organism that is neuroanatomically and molecularly similar to humans (Bayés et al., 2011). Many useful models are available, that show varying signs of cognitive decline and synaptic loss, but none reflect the full cascade of pathology including neuronal death (Jucker, 2010). Thus, approaches are required that can reconcile the range of molecular abnormalities in different mouse models of disease and identify affected molecular pathways.

In vivo metabolic labelling and global proteomic profiling has the capacity to measure the dynamics of individual proteins throughout the proteome (Hinkson and Elias, 2011; Krüger et al., 2008; Larance and Lamond, 2015; McClatchy et al., 2007; Schwanhäusser et al., 2011). Here, we first established a method using ${ }^{13} \mathrm{C}$ heavy lysine (K6) labelling to detect global proteome turnover change in mice. Next, we developed the assay to simultaneously measure changes in protein turnover and expression level in vivo. This multiplex screen of proteome dynamics is applicable to any protein in any tissue and distinguishes between changes driven by synthesis or degradation of a protein. We applied this screen to quantify 1000 proteins in three mouse models of neurodegenerative disease at presymptomatic and symptomatic ages. In all models that we tested, increased neuropathology is associated with increased protein turnover and changes in the 
amount of some specific proteins, caused by measurable alterations in their synthesis or degradation. Finally, we used the method to investigate the proteome dynamics that are associated with ageing in healthy mice. Global protein turnover decreased with age, which was associated with a slowdown in autophagy. This resource reveals novel signatures of pathology, facilitates comparisons between different mouse models of disease and contrasts neurodegeneration with the mechanisms of ageing.

\section{RESULTS}

\section{Detecting proteome turnover in mouse models of disease}

There are multiple approaches capable of measuring protein turnover (Doherty et al., 2005; Heo et al., 2018; Larance et al., 2011; Price et al., 2010a; Savitski et al., 2018). We devised a simple approach that matched the following three criteria: 1) Requires minimal experimental design, 2) is amenable to cohorts of multiple test and control mice, and 3) enables straightforward identification of peptides, label incorporation and turnover. To quantify changes in protein turnover, mice were fed a diet in which the essential amino acid, lysine $(\mathrm{K} 0)$, was replaced with a ${ }^{13} \mathrm{C}$ stable isotope derivative $(\mathrm{K} 6)$ for 6-8 days (Figure $1 \mathrm{~A})$. The rate of $\mathrm{K} 6$ incorporation was directly quantified by the ratio of $\mathrm{K} 6$ to $\mathrm{KO}$ in each mouse. We benchmarked the accuracy of identifying heavy-light peptide pairs using a decoy unlabelled dataset, which indicated an empirical FDR of $2 \%$ and $0.01 \%$ using single and double counting of K0-K6 pairs, respectively. Therefore, double counts were used throughout.

To validate this simple method of measuring changes in protein turnover and its applicability to neurodegenerative disease we used TgCRND8 mice, an aggressive transgenic mouse model of familial Alzheimer's disease (AD) that overexpresses hAPP (Chishti et al., 2001). This mouse line develops several pathologies characteristic of $A D$ including $\beta$-amyloid plaques, synapse loss, and behavioural phenotypes (Chishti et al., 2001). Three 3-month-old TgCRND8 and 
three age-, sex- and genetic background-matched control mice were labelled with K6 food for 6 days. At the end of this labelling period the hippocampi from these mice were collected for LC-MS (Figure 1A). Measuring the change in K6 incorporation between disease and control tissues gave a snapshot of proteome turnover associated with the disease.

In each tissue sample from each mouse we identified an average of 72,261 peptides $( \pm 4,231 \mathrm{sd})$, with a total of 130,516 unique peptides identified in the cohort. Of this total, 67,416 peptides contained at least a single lysine residue, and we identified light-heavy (K0-K6) labelled peptide pairs in $41.25 \%$ of them, enabling the quantification of label incorporation in 27,752 peptides (Table S1). Overall, these data gave rise to 10,973 ( $\pm 392 \mathrm{sd}$ ) identified proteins and K6 incorporation was quantified in 2,685 ( $\pm 190 \mathrm{sd})$ proteins per tissue sample. The change in turnover was calculated using proteins detected in at least two mice from each cohort, giving a screen that measured 1392 protein turnover changes in the TgCRND8 hippocampus with high-quality MS data. A few proteins were absent from the screen because they contain very few lysine-containing peptides. One example of these proteins, ApoE, was of particular interest due to its association with $A D$. Therefore, to quantify these extremely scarce ApoE peptides, we enriched samples by immuno-affinity purification before MS analysis (Figure S1). In principle therefore, this in vivo approach can detect changes in protein turnover of any lysine-containing protein in any tissue.

Incorporation of $\mathrm{K} 6$ ranged from 1.4 to $70.9 \%$, indicative of a large dynamic range of protein turnover. Remarkably, although there is minimal $\beta$-amyloid pathology at this age (Figure 1B and Table S1), an overall 6.1\% slowdown in the global average protein turnover (GAPT) was measured in TgCRND8 hippocampus ( $P=$ $0.0037 \mathrm{n}=1392$, Figure $1 \mathrm{C})$. In contrast, serum $(P=0.128, \mathrm{n}=118)$ and liver $(P=$ 0.17, $\mathrm{n}=590$ ) protein turnover did not change significantly (Figure 1D-E), indicating that the decrease in protein turnover is specific to the pathologically affected forebrain tissue. As a further control to account for amino acid recycling rates, the precursor $\mathrm{K} 6$ concentration was determined using peptides containing 
more than one lysine in disease and control samples (Doherty et al., 2005; Hellerstein and Neese, 1992). No difference was detected (Table S2), indicating that changes in $\mathrm{K} 6$ incorporation directly measure changes in protein turnover.

If turnover changes are associated with $\beta$-amyloidosis, then as pathology progresses one would expect protein turnover changes to reflect the increasing load of $\beta$-amyloid pathology. To test this possibility, we repeated our turnover measurement at P285, by which age TgCRND8 have pervasive amyloid deposits throughout the forebrain (Figure 2A, top, and Table S1). Surprisingly, examination of the protein turnover in the older TgCRND8 model did not extend the slowdown that was seen at 113 days of age. Instead, at 285 days of age, an $18 \%$ increase in GAPT hippocampal protein turnover $(P<0.0001, \mathrm{n}=847$, Figure $2 \mathrm{~A}, \mathrm{~B})$, whereas in serum protein GAPT was unchanged, indicating the change in proteome flux was restricted to the locus of $\beta$-amyloidosis. Overall, these proteome turnover data indicate discordance in proteome kinetics between early and late stages of pathology in the TgCRND8 model of AD.

\section{Proteome turnover in the $A p p^{N L / F}$ knockin mouse model of $A D$}

In progressive diseases, identifying protein turnover changes that precede pathology could indicate upstream molecular pathways involved in the disease. However, in transgenic models of disease, including TgCRND8, one cannot distinguish between bone fide pathological mechanisms and effects that result from ectopic over-expression of the APP precursor. Therefore to test in the absence of over-expression, we used a knockin mouse model of familial AD, $A p p^{N L-F / N L-F}$, which lacks these potential artefacts (Saito et al., 2014). Protein turnover was measured at P186 and P548, which are time-points before and after widespread $\beta$-amyloid pathology, respectively.

In pre-symptomatic P186 App ${ }^{N L-F / N L-F}$ forebrain, no significant change in GAPT was detected (Figure 2C,D). However, in P548 App ${ }^{N L-F / N L-F}$ mice with advanced $\beta$ amyloidosis, forebrain GAPT increased by $15.7 \%(P<0.0001, \mathrm{n}=721)$, with 53 
proteins being made or degraded faster (Figure 2E and Table S1). No significant change was detected in serum proteins (Figure 2F). Thus, an increase in protein flux is associated with increasing pathology in the $A p p^{N L-F / N L-F}$ knockin mouse model of $\beta$-amyloidosis.

\section{Protein turnover in tissue undergoing cell death}

Late stages of neurodegenerative diseases are characterized by widespread neuronal death. To test for proteome turnover changes in tissues undergoing neuronal death we K6-labelled 3-month-old TgSOD1-G93A mice (Gurney et al., 1994), a mouse model of familial amyotrophic lateral sclerosis (ALS). At this age, TgSOD1-G93A mice displayed rear gait phenotypes (Gurney et al., 1994), indicating spinal cord pathology and extensive neurodegeneration. In TgSOD1G93A spinal cord GAPT increased $17.7 \%$ in the diseased mice compared to control $(P=0.0001, \mathrm{n}=496$, Figure $2 \mathrm{G}, \mathrm{H}$ and Table S1). In contrast, plasma protein GAPT was unchanged $(P=0.417, \mathrm{n}=89)$. Overall, in all models at late stages a marked increase in overall protein flux was detected. These data could give insight into the particular pathways. However, this raises the question, whether or not increased turnover is coupled to the gain or loss in the expression levels of proteins, or if the increased turnover corresponds to the futile cycles of increased repair.

\section{Dynaplot: a comprehensive map of proteome dynamics}

The kinetics of protein turnover drives the expression level of all proteins (Ohsumi, 2006). Therefore, the simultaneous measurement of turnover and expression level of each protein can give a comprehensive description of proteome dynamics and mechanistic insight. Having established a method for screening changes in protein turnover, we next combined turnover measurements with expression level measurements by exploiting recent improvements of label-free quantification (MaxLFQ) (Cox et al., 2014). In each mouse model of disease dataset, an average 
of 4357 proteins $( \pm 654 \mathrm{sd})$ were quantified by label-free quantification (Table S3). Proteins were quantified in all mice in $98.0 \% \quad( \pm 2.0 \%)$ of the proteins that were used for turnover analysis, giving excellent reproducibility.

Plotting turnover versus steady state expression level changes (hereon referred to as a dynaplot) is potentially a powerful tool because the coordinate space of these measurements infers the mechanism of change, as depicted in Figure 3A. In principle, changes in turnover can be regulated by either the rate of synthesis or degradation. Therefore, six scenarios arise: 1) Increased steady state levels driven by an increase in protein turnover, indicates the net synthesis rate has increased. 2) Increased steady state levels can also be driven by a net decrease in turnover, which reflects a decrease in the rate of protein degradation. Similarly, two distinct mechanisms for decreasing the steady state level of proteins can be directly inferred: 3) Decreased steady state levels driven by a decrease protein turnover, which is the result of a net decrease in protein synthesis, and 4) decreased steady state levels driven by an net increase in protein turnover, which is driven by a net increase in degradation. Finally, proteins can occupy coordinate space on the dynaplot in which 5) increases or 6) decreases in protein turnover are uncoupled from steady state changes. These futile cycles reflect an increase and decrease in the rate of protein repair, respectively.

A dynaplot showing the change in flux versus the expression level of each protein is depicted in Figure3. In each disease mouse model imbalances in turnover resulted in changes in expression level of a subset of the proteome (Figure 3B-F). Comparing 6-month and 18-month-old $A p p^{N L-F / N L-F}$ showed a 5-fold increase in the number of significantly changed proteins (Figure 3D,E and Table S3). Thus, increased pathology correlated with increased imbalances in the proteome. However, different proteins were differentially affected, suggesting different pathways are impacted at early and late stages of pathology (Table S4). Analysis of the symptomatic App $p^{N L-F / N L-F}$ dataset using the KEGG showed that significantly changed proteins converged on several pathways that appear to be prevalent in presynaptic functions, including synaptic vesicle recycling and mitochondria 
(Figure 4). Thus, multidimensional proteome dynamics have identified specific proteins and pathways dysregulated as a consequence of disease (Table S3).

\section{Proteome dynamics of ageing and autophagic flux}

Ageing is the greatest known risk factor for developing neurodegenerative disease, including AD (Blennow et al., 2006). It is commonly held that protein turnover slows with age (Dwyer et al., 1980; Makrides, 1983). Therefore, we measured the change in proteome dynamics associated with ageing in wildtype mice varying in age from 3 to 17 months (Figure 5A and Table S5). Strikingly, $98 \%$ of the proteins measured showed decreasing $\mathrm{K} 6$ incorporation with age (between 113 and 503 days of age, $P=6.2 \times 10^{-16}, \mathrm{n}=360$ ). Thus, the global average protein turnover decreased significantly with age (Figure $5 \mathrm{~A}$ ). Since the $\mathrm{K} 6$ label is delivered by diet, as a control we measured average food consumption, which indicated no decline in food consumption with age (Figure 5B). The average levels of protein abundance did not change significantly (Figure 5C and Table S5), consistent with earlier reports (Walther and Mann, 2011). Overall, these ageing data could provide a rich resource for exploring molecular mechanisms associated with ageing.

Next, we explored our proteome dynamics dataset to identify potential mechanisms that could explain the ageing-associated global decrease in proteome turnover, focusing on mechanisms that could drive proteome wide changes. One such candidate is autophagy, the dynamics of which are challenging to follow (Loos et al., 2014; Schmidt et al., 2009). A prominent marker of autophagy is LC3, and this showed a significant decrease in K6 incorporation that was tightly associated with ageing (Figure 5D). However, the steady state levels of LC3 fluctuated but did not correlate with increasing age (Table S5). Thus, autophagic flux decreases with age and provides a mechanism that in part explains the global decrease in proteome turnover.

\section{DISCUSSION}


Using a novel combination of live mouse labelling and proteomic profiling, we have developed a method for simultaneously measuring the flux of proteome wide changes in turnover and steady-state expression levels. By combining both measurements, this approach distinguishes changes that are mediated protein synthesis versus degradation and enables the direct estimate of changes in protein flux. We tested this method in multiple mouse models of disease, which revealed global effects as well as identifying individual pathways associated with pathology. Next, we applied the method to ageing in wildtype mice, and observed a decline in protein turnover that could be partially explained by a decline in vivo autophagic flux.

This methodological framework should be especially useful for identifying proteins and molecular pathways in other live animal test settings, including disease models, learning and behaviour (Shen et al., 2014). Establishing the cause of an imbalance in turnover could be essential for understanding diseases, and is likely to highlight new targets for pharmaceutical intervention. Indeed, there is a growing body of evidence that correcting imbalances in proteome dynamics can slow the onset of disease symptoms (Das et al., 2015; Moreno et al., 2012).

There is also increased appreciation that better mouse models are needed to identify targets for therapeutic intervention in neurodegenerative diseases, including AD (Drummond and Wisniewski, 2017). The comprehensive proteome dynamics provided insights that enable the direct comparison of multiple different mouse models (Savas et al., 2017). Comparing the over-expressing hAPP transgenic model (TgCRND8) at early and late stages of the disease indicated large yet discordant effects on protein turnover. Since changes did not correlate with increasing pathology it is difficult to distinguish molecular mechanisms altered by over-expression of the transgene from changes associated with $\beta$-amyloidosis in this mouse line. In contrast, turnover changes identified in models that do not rely on ectopic over-expression, (App ${ }^{N L-F / N L-F}$ knockin model) were correlated with increased pathology. 
In all models tested at symptomatic stages, global average protein turnover increased suggesting a disease-associated proteome-wide state of repair. Increased proteomic flux drove expression level imbalances caused by increased synthesis of one subset of the proteome and increased degradation of another (Figure 3 and Table S4). This is consistent with transcriptomic data from AD postmortem samples that suggested increased autophagy-mediated turnover (Lipinski et al., 2010). It is likely transcriptional programmes are involved in regulating the increase in proteome flux (Matarin et al., 2015). Also, an increased flux of $A \beta$ has been detected in familial AD patients (Potter et al., 2013).

In contrast to disease, it is intriguing that turnover declines as wildtype mice age, whereas steady state levels of the proteome in mice appear to show no global change associated with age (Walther and Mann, 2011). This is consistent with similar reports of proteome turnover decline in invertebrates (Walther et al., 2015), albeit expression levels in ageing invertebrates appear to change (Narayan et al., 2016; Walther et al., 2015). Our turnover measurements of LC3 enabled an estimation of autophagic flux, which also declined with ageing, suggesting the global turnover decrease associated with ageing could, at least in part, be mediated by slowdown in autophagy.

Overall, it is striking that while ageing is associated with a decrease in flux, all three neurodegenerative disease models caused an increase in flux. Thus, these mouse models suggest neurodegenerative diseases are not an acceleration of ageing, but rather represent a state of proteome imbalance and increased repair. As improved models of neurodegenerative disease are developed, applying comprehensive proteome dynamics is expected to give important phenotypic, molecular, and mechanistic insight. 


\section{STAR methods}

\section{KEY RESOURCES TABLE}

\begin{tabular}{|c|c|c|}
\hline REAGENT or RESOURCE & SOURCE & IDENTIFIER \\
\hline \multicolumn{3}{|l|}{ Antibodies } \\
\hline Mouse monoclonal (4G8) anti- $\beta$-Amyloid (17-24) & BioLegend & $\begin{array}{l}\text { Cat\# } 800701 \\
\text { AB_2313891 }\end{array}$ \\
\hline Mouse monoclonal (6E10) anti- $\beta$-Amyloid (1-16) & BioLegend & $\begin{array}{l}\text { Cat\# } 803015 \\
\text { AB_10102028 }\end{array}$ \\
\hline Rabbit polyclonal anti-PSD95 & Abcam & $\begin{array}{l}\text { Cat\# ab18258 } \\
\text { AB_444362 }\end{array}$ \\
\hline Rabbit monoclonal (16H22L18) anti-ApoE & Thermo & $\begin{array}{l}\text { Cat\# } 701241 \\
\text { AB_2532438 }\end{array}$ \\
\hline Mouse monoclonal (D6E10) anti-ApoE & Abcam & $\begin{array}{l}\text { Cat\# ab1906 } \\
\text { AB_302668 }\end{array}$ \\
\hline \multicolumn{3}{|l|}{ Deposited Data } \\
\hline Raw and database-matched mass spec data & This paper & PRIDE: PXD010671 \\
\hline \multicolumn{3}{|l|}{ Experimental Models: Organisms/Strains } \\
\hline TgCRND8 & David Westaway & PMID: 11279122 \\
\hline$A p p^{N L-F}$ & Takaomi Saido & PMID: 24728269 \\
\hline TgSOD1-G93A & Jackson Labs & PMID: 8209258 \\
\hline \multicolumn{3}{|l|}{ Software and Algorithms } \\
\hline MaxQuant & Cox and Mann, 2008 & $\begin{array}{l}\text { http://www.coxdocs. } \\
\text { org/doku.php?id=ma } \\
\text { xquant:common:dow } \\
\text { nload_and_installati } \\
\text { on }\end{array}$ \\
\hline Perseus & Tyanova et al, 2016 & $\begin{array}{l}\text { http://www.coxdocs. } \\
\text { org/doku.php?id=per } \\
\text { seus:common:downl } \\
\text { oad_and_installation }\end{array}$ \\
\hline Prism & Commercial software & $\begin{array}{l}\text { https://www.graphpa } \\
\text { d.com/scientific- } \\
\text { software/prism/ }\end{array}$ \\
\hline $\mathrm{R}$ & Open source & $\begin{array}{l}\text { https://www.r- } \\
\text { project.org/ }\end{array}$ \\
\hline
\end{tabular}

\section{CONTACT FOR REAGENT AND RESOURCE SHARING}

Further information and requests for resources and reagents should be directed to and will be fulfilled by the lead contact René A. W. Frank (rene@mrcImb.cam.ac.uk)

\section{EXPERIMENTAL MODEL AND SUBJECT DETAILS}




\section{Mice}

Animals were treated in accordance with UK Animal Scientific Procedures Act (1986) and NIH guidelines. Several mouse models of neurodegeneration were used in this work. Two models of $\beta$-amyloidosis were used, the TgCRND8 transgenic mouse and the App ${ }^{N L-F / N L-F}$ knock-in mouse (Chishti et al., 2001; Saito et al., 2014). The SOD1-G93A mice modelled ALS (Gurney et al., 1994). Genotyping was performed on every mouse by the LMB in-house facility. Age-, sex- and genetic background matched mice were used in test and control groups.

\section{METHOD DETAILS}

\section{Metabolic labelling of live mice}

Mouse proteins were globally labelled ${ }^{13} \mathrm{C}$ heavy lysine (Lysine-6; K6) by feeding with mice Lys-6 food (Silantes, Germany) for 6-8 days. All transgenic models of disease were fed $\mathrm{K} 6$ food for 6 days, as were the control mice used in the ageing analysis. To counteract the decline in protein turnover that is observed in age (Figure 5), the 18-month-old $A p p^{N L-F / N L-F}$ and control of mice were fed for eight days. Mice were kept in cages separated by genotype, and labelled in groups of six: three control and three experimental mice. The mass of each mouse and food consumed were recorded throughout the experiments and the primary control for assessing the level of heavy label incorporation was the measurement of plasma protein turnover.

At the end of the labelling period, the mice were culled and all major organs were collected and immediately frozen in liquid nitrogen, including blood plasma and cerebrospinal fluid. The brain was dissected into eight separate regions, and each area was frozen individually and immediately (olfactory bulb, caudate putamen, hippocampus, cortex, colliculus, cerebellum, thalamus and hindbrain).

\section{Mouse tissue fractionation}

Mice were culled by cervical dislocation or by overdose of pentobarbital. Organs were immediately dissected on ice, including the separation of brain areas and 
harvesting of cerebrospinal fluid, and all tissue and humours were snap frozen in liquid nitrogen. Tissue was homogenised manually in $\mathrm{H}$ buffer (320 mM sucrose, 2 mM HEPES at $\mathrm{pH} 7.3$ with protease inhibitors). Volumes of $\mathrm{H}$ buffer were scaled to mass of tissue (232 $\mathrm{mg}$ tissue $=5 \mathrm{ml} \mathrm{H}$ buffer). Nuclei were pelleted by centrifugation at $1 \mathrm{k} \times \mathrm{g}$, and this pellet was homogenised for a second time in $\mathrm{H}$ buffer and pelleted as above. Membranes were pelleted from the supernatant at $21 \mathrm{k} \times \mathrm{g}$ and all fractions were divided into small portions and flash-frozen in liquid nitrogen. This procedure was applied to hippocampus, cortex and spinal cord. Plasma proteins were diluted 1:40 with PBS and added to LDS sample buffer (Thermo) directly. For extraction, tissue fraction pellets were resuspended in $\mathrm{H}$ buffer, and extraction/precipitation buffer added to the suspension as appropriate. Extraction/precipitation buffer consisted of $25 \mathrm{mM}$ Tris, $\mathrm{pH} 8,50 \mathrm{mM} \mathrm{NaCl}, 2 \mathrm{mM}$ TCEP, protease inhibitors, benzonase (Novagen) and detergent - proteins from the membranes were solubilised in deoxycholate or Triton X-100 $(0.8 \% \mathrm{w} / \mathrm{v}$ or $1 \%$ $\mathrm{v} / \mathrm{v}$ final, respectively) and proteins from the nuclear fraction were precipitated in Triton X-100 or GDN (1\% final). Solubilised material was cleared by ultracentrifugation at $120 \mathrm{k} \times \mathrm{g}$ for $40 \mathrm{mins}, 8 \mathrm{C}$ and precipitated material was pelleted by centrifugation at $21 \mathrm{k} \times \mathrm{g}$ for $25 \mathrm{mins}, 8 \mathrm{C}$. Solubilised or precipitated material was prepared for SDS-PAGE by addition of LDS sample buffer and cysteines were alkylated with $10 \mathrm{mM}$ iodoacetamide prior to electrophoresis through $1 \mathrm{~mm}$ thick $4-12 \%$ Bis-Tris acylamide gels (Thermo). Proteins were stained with colloidal Coomassie blue, and 16 sections, each $4 \times 4 \mathrm{~mm}$, were cut from each sample lane and diced into $1 \mathrm{~mm}$ cubes separately. These polyacrylamide cubes containing the fractionated proteins were prepared for mass spectrometric analysis using the Janus liquid handling system (PerkinElmer, UK). Briefly, the excised protein gel pieces were placed in a well of a 96-well microtitre plate and destained with $50 \% \mathrm{v} / \mathrm{v}$ acetonitrile and $50 \mathrm{mM}$ ammonium bicarbonate, reduced with $10 \mathrm{mM}$ DTT, and post-alkylated with $55 \mathrm{mM}$ iodoacetamide. After alkylation, proteins were digested with $6 \mathrm{ng} / \mu \mathrm{L}$ trypsin (Promega, UK) overnight at $37{ }^{\circ} \mathrm{C}$. The resulting peptides were extracted in $2 \% \mathrm{v} / \mathrm{v}$ formic acid, $2 \% \mathrm{v} / \mathrm{v}$ acetonitrile. In some cases, the peptides extracted from 16 gel sections were combined into 4 samples for LC-MS. The conditions of detergent fractionations 
and digestion with trypsin were chosen from several rounds of optimisation experiments to maximise peptide coverage and quantification.

\section{Mass spectrometry and data analysis}

The protein digest was analysed by nano-scale capillary LC-MS/MS using an Ultimate U3000 HPLC (ThermoScientific Dionex, San Jose, USA) to deliver a flow of approximately $300 \mathrm{~nL} / \mathrm{min}$. A C18 Acclaim PepMap100 $5 \mu \mathrm{m}, 100 \mu \mathrm{m}$ x $20 \mathrm{~mm}$ nanoViper (ThermoScientific Dionex, San Jose, USA), trapped the peptides prior to separation on a C18 Acclaim PepMap100 $3 \mu \mathrm{m}, 75 \mu \mathrm{m} \times 250 \mathrm{~mm}$ nanoViper (ThermoScientific Dionex, San Jose, USA). Peptides were eluted with a 120 minute gradient of acetonitrile ( $2 \%$ to $50 \%$ ). The analytical column outlet was directly interfaced, via a nano-flow electrospray ionisation source, with a hybrid quadrupole orbitrap mass spectrometer (Q-Exactive Plus Orbitrap, ThermoScientific, San Jose, USA). Data dependent analysis was carried out, using a resolution of 30,000 Da for the full MS spectrum, followed by ten MS/MS spectra. MS spectra were collected over a m/z range of 300-2000. MS/MS scans were collected using a threshold energy of 27 for higher energy collisional dissociation (HCD). Each tryptic peptide containing lysine-6 produced a peptide ion pair differing by $6.02 \mathrm{Da}$ (divided by charge state).

For SILAM analysis of protein turnover, peptide pairs were located with MaxQuant 1.5.0 and identified with Andromeda using a reviewed version of the mouse Uniprot database. Each detergent fraction was analysed with MaxQuant individually, and quantified proteins were forwarded for analysis if they were found in at least two of three biological replicates in both control and experimental animals. A final non-redundant merged dataset was generated excluding quantifications of the same protein from different detergent fractions; keeping the protein measurement with the greatest difference in Lysine-6 incorporation between the control and experimental animals. Two-tailed Student's $T$ tests $(p=$ 0.05) were performed on the ratios of incorporation in control and experimental animals. As detailed in figure 1a, the SILAM ratio is a direct readout of protein turnover. 
For Label-Free Quantification of the same datasets, the maxLFQ functionality of MaxQuant 1.5.0 was used. However, proteins in each detergent fraction were forwarded for subsequent analysis if they were found in every single mouse of that fraction (six of six). The protein quantification data were integrated by averaging the quantities from each high-quality detergent fraction together on a mouse-bymouse basis. Two-tailed Student's T tests $(p=0.05)$ were performed on the levels of protein in control and experimental animals.

Importantly, it was essential to observe the peptide pairs at least twice, by using a double count requirement for quantification in MaxQuant. We found experimentally that if the pairs of peptides were measured only in only a single scan, peptide ratios were erroneously found in over $2 \%$ of identified proteins in an unlabelled sample (57 ratios in 2733 identifications, data not shown).

\section{Immunohistochemistry}

Mice were euthanized by cervical dislocation or by overdose of pentobarbital when they were transcardially perfused with PBS. Brains were divided along the midline and half was submerged in OCT (optimal cryotomy) solution in a cut-away plastic mould - the other half was kept for biochemical analysis. OCT-submerged brains were frozen by submersion of the mould into a beaker of isopentane that was subsequently chilled in liquid nitrogen. The frozen brain sections were cut at a thickness of 14 um using a cryostat (Leica) and post-fixed using freezing methanol. Sections were blocked using 3\% BSA or 10\% goat serum in PBS with $0.2 \%$ Triton X-100, and probed with primary antibodies [Mouse anti-Abeta (6E10; Covance, 803001) and Rabbit anti-PSD95 (Abcam, ab18258] overnight at $4 \mathrm{C}$. Secondary antibodies were conjugated to Alexafluor 488 or 647 (Thermo) and were applied to the samples for two hours before mounting the slide using ProLong Antifade mountant with DAPI (Thermo). Images were acquired using a Zeiss 780 confocal microscope then viewed and analysed in Fiji. All antibody 
combinations were validated by controls with individually absent primary antibodies.

\section{Immuno-affinity protein purification}

Frozen membrane fractions were resuspended in $\mathrm{H}$ buffer and solubilised in DOC extraction buffer (as above) for 1 hour. The extract was cleared by ultracentrifugation (120k x g, 40 mins, $8 \mathrm{C}$ ). Antibodies were added to the cleared extract and left to bind overnight at $4 \mathrm{C}$. The antibodies and adsorbed proteins were reclaimed by the addition of protein G Dynabeads (Sigma) for 40 mins the following day. After washing twice with a solution containing $25 \mathrm{mM}$ Tris, $\mathrm{pH} 8$ and $50 \mathrm{mM} \mathrm{NaCl}$, the antibodies and the adsorbed proteins were eluted with SDS.

\section{Functional clustering analysis}

Proteins that changed their turnover dynamics were functionally clustered by the DAVID online tool (https://david.abcc.ncifcrf.gov/home.jsp), using KEGG pathways. Functional annotation charts were exported and visualized using String (Szklarczyk et al., 2017) to depict experimentally determined protein-protein interactions.

\section{QUANTIFICATION AND STATISTICAL ANALYSIS}

\section{Statistics}

Data were analyzed with PRISM 5 (GraphPad). Data are presented as mean and error bars represent SEM. All experiments were performed in at least three independent biological replicates. Details of statistical tests used and $p$ values are presented in the figure legends.

${ }^{*} p \leq 0.05,{ }^{* *} p \leq 0.01,{ }^{* * *} p \leq 0.001,{ }^{* * * *} p \leq 0.0001$, ns: non-significant.

\section{DATA AND SOFTWARE AVAILABILITY}

Proteomic data deposition

All data were deposited in the PRIDE database, project accession: PXD010671.

\section{Acknowledgements}


We thank the staff of the MRC Laboratory of Molecular Biology's Animal Facility. We would also like to thank Nick Barry, Mathias Pasche, and Jonathan Howe for light microscopy support. Jake Grimmet and Toby for computational infrastructure support. Sebastian Schmidt (Silantes) for technical support with SILAM labelling. We would also like to thank Michel Goedert, Harvey McMahon, Nushan Pasindu Gunawardana, Toke Hansen, Isabelle Lavenir, Jennifer McDonald and Ben Falcon (MRC LMB) for insightful discussions. The research leading to these results received core funding from the Medical Research Council and a pump priming grant from Alzheimer's Research UK. 


\section{References}

Bayés, A., van de Lagemaat, L.N., Collins, M.O., Croning, M.D.R., Whittle, I.R., Choudhary, J.S., Grant, S.G.N., 2011. Characterization of the proteome, diseases and evolution of the human postsynaptic density. Nature neuroscience 14, 19-21. doi:10.1038/nn.2719

Blennow, K., de Leon, M.J., Zetterberg, H., 2006. Alzheimer's disease. The Lancet 368, 387-403. doi:10.1016/S0140-6736 (06)69113-7

Braak, H., Braak, E., 1991. Neuropathological stageing of Alzheimer-related changes. Acta Neuropathol 82, 239-259.

Chishti, M.A., Yang, D.S., Janus, C., Phinney, A.L., Horne, P., Pearson, J., Strome, R., Zuker, N., Loukides, J., French, J., Turner, S., Lozza, G., Grilli, M., Kunicki, S., Morissette, C., Paquette, J., Gervais, F., Bergeron, C., Fraser, P.E., Carlson, G.A., George-Hyslop, P.S., Westaway, D., 2001. Early-onset amyloid deposition and cognitive deficits in transgenic mice expressing a double mutant form of amyloid precursor protein 695. J Biol Chem 276, 21562-21570. doi:10.1074/jbc.M100710200

Cox, J., Hein, M.Y., Luber, C.A., Paron, I., Nagaraj, N., 2014. Accurate proteomewide label-free quantification by delayed normalization and maximal peptide ratio extraction, termed MaxLFQ. Molecular \& Cellular .... doi:10.1074/mcp

Crick, F., 1984. Memory and molecular turnover. Nature 312, 101.

Das, I., Krzyzosiak, A., Schneider, K., Wrabetz, L., 2015. Preventing proteostasis diseases by selective inhibition of a phosphatase regulatory subunit. Science.

De Strooper, B., Karran, E., 2016. The Cellular Phase of Alzheimer's Disease. Cell 164, 603-615. doi:10.1016/j.cell.2015.12.056

Doherty, M.K., Whitehead, C., McCormack, H., Gaskell, S.J., Beynon, R.J., 2005. Proteome dynamics in complex organisms: Using stable isotopes to monitor individual protein turnover rates. Proteomics 5, 522-533. doi:10.1002/pmic.200400959

Drummond, E., Wisniewski, T., 2017. Alzheimer's disease: experimental models and reality. Acta Neuropathol 133, 155-175. doi:10.1007/s00401-016-1662-x

Dubois, B., Hampel, H., Feldman, H.H., Scheltens, P., Aisen, P., Andrieu, S., Bakardjian, H., Benali, H., Bertram, L., Blennow, K., Broich, K., Cavedo, E., Crutch, S., Dartigues, J.-F., Duyckaerts, C., Epelbaum, S., Frisoni, G.B., Gauthier, S., Genthon, R., Gouw, A.A., Habert, M.-O., Holtzman, D.M., Kivipelto, M., Lista, S., Molinuevo, J.L., O'Bryant, S.E., Rabinovici, G.D., Rowe, C., Salloway, S., Schneider, L.S., Sperling, R., Teichmann, M., Carrillo, M.C., Cummings, J., Jack, C.R., Jr, USA,

P.O.T.M.O.T.I.W.G.I.A.T.A.A.A.O.T.P.S.O.A.J.2.2.W.D., 2016. Preclinical Alzheimer's disease: Definition, natural history, and diagnostic criteria. Alzheimer's \& Dementia 12, 292-323. doi:10.1016/j.jalz.2016.02.002

Dwyer, B.E., Fando, J.L., Wasterlain, C.G., 1980. Rat brain protein synthesis declines during postdevelopmental aging. J Neurochem 35, 746-749.

Eisenberg, D., Jucker, M., 2012. The Amyloid State of Proteins in Human Diseases. Cell 148, 1188-1203. doi:10.1016/j.cell.2012.02.022 
Goedert, M., 2015. Alzheimer"s and Parkinson"s diseases: The prion concept in relation to assembled A, tau, and -synuclein. Science 349, 12555551255555. doi:10.1126/science. 1255555

Goldberg, A.L., 2003. Protein degradation and protection against misfolded or damaged proteins. Nature 426, 895-899. doi:10.1038/nature02263

Guerreiro, R., Hardy, J., 2014. Genetics of Alzheimer's disease. Neurotherapeutics 11, 732-737. doi:10.1007/s13311-014-0295-9

Gurney, M.E., Pu, H., Chiu, A.Y., Canto, M.D., Polchow, C.Y., Alexander, D.D., Caliendo, J., Hentati, A., Kwon, Y.W., Deng, H.X., et, al, 1994. Motor neuron degeneration in mice that express a human $\mathrm{Cu}, \mathrm{Zn}$ superoxide dismutase mutation. Science 264, 1772-1775. doi:10.1126/science.8209258

Hardy, J., Bogdanovic, N., Winblad, B., Portelius, E., Andreasen, N., CedazoMinguez, A., Zetterberg, H., 2014. Pathways to Alzheimer's disease. J. Intern. Med. 275, 296-303. doi:10.1111/joim.12210/pdf

Harris, H., Rubinsztein, D.C., 2011. Control of autophagy as a therapy for neurodegenerative disease. Nature Publishing Group 8, 108-117. doi:10.1038/nrneurol.2011.200

Hellerstein, M.K., Neese, R.A., 1992. Mass isotopomer distribution analysis: a technique for measuring biosynthesis and turnover of polymers. Am J Physiol Endocrinol Metab 263, E988-1001.

Heo, S., Diering, G.H., Na, C.H., Nirujogi, R.S., Bachman, J.L., Pandey, A., Huganir, R.L., 2018. Identification of long-lived synaptic proteins by proteomic analysis of synaptosome protein turnover. Proceedings of the National Academy of Sciences 41, 201720956-10. doi:10.1073/pnas.1720956115

Hinkson, I.V., Elias, J.E., 2011. The dynamic state of protein turnover: It's about time. Trends in Cell Biology 21, 293-303. doi:10.1016/j.tcb.2011.02.002

Jucker, M., 2010. The benefits and limitations of animal models for translational research in neurodegenerative diseases. Nat Med 16, 1210-1214. doi:10.1038/nm.2224

Kim, Y.E., Hosp, F., Frottin, F., Ge, H., Mann, M., Hayer-Hartl, M., Hartl, F.U., 2016. Soluble Oligomers of PolyQ-Expanded Huntingtin Target a Multiplicity of Key Cellular Factors. Molecular Cell 63, 951-964. doi:10.1016/j.molcel.2016.07.022

Krüger, M., Moser, M., Ussar, S., Thievessen, I., Luber, C.A., Forner, F., Schmidt, S., Zanivan, S., Fässler, R., Mann, M., 2008. SILAC Mouse for Quantitative Proteomics Uncovers Kindlin-3 as an Essential Factor for Red Blood Cell Function. Cell 134, 353-364. doi:10.1016/j.cell.2008.05.033

Larance, M., Bailly, A.P., Pourkarimi, E., Hay, R.T., Buchanan, G., Coulthurst, S., Xirodimas, D.P., Gartner, A., Lamond, A.I., 2011. Stable-isotope labeling with amino acids in nematodes. Nature Methods 8, 849-851.

doi:10.1038/nmeth.1679

Larance, M., Lamond, A.I., 2015. Multidimensional proteomics for cell biology. Nature Publishing Group 16, 269-280. doi:10.1038/nrm3970

Lipinski, M.M., Zheng, B., Lu, T., Yan, Z., Py, B.F., Ng, A., Xavier, R.J., Li, C., Yankner, B.A., Scherzer, C.R., Yuan, J., 2010. Genome-wide analysis reveals mechanisms modulating autophagy in normal brain aging and in Alzheimer's disease. Proceedings of the National Academy of Sciences 107, 1416414169. doi:10.1073/pnas. 1009485107 
Lisman, J., Yasuda, R., Raghavachari, S., 2012. Mechanisms of CaMKII action in long-term potentiation. Nat Rev Neurosci 358, 1-14. doi:10.1038/nrn3192

Loos, B., Toit, du, A., Hofmeyr, J.-H.S., 2014. Defining and measuring autophagosome flux - concept and reality. autophagy 10, 2087-2096. doi:10.4161/15548627.2014.973338

Makrides, S.C., 1983. Protein synthesis and degradation during aging and senescence. Biol Rev Camb Philos Soc 58, 343-422. doi:10.1111/j.1469185X.1983.tb00394.X

Masters, C.L., Selkoe, D.J., 2012. Biochemistry of Amyloid -Protein and Amyloid Deposits in Alzheimer Disease. Cold Spring Harbor Perspectives in Medicine 2, a006262-a006262. doi:10.1101/cshperspect.a006262

Matarin, M., Salih, D.A., Yasvoina, M., Cummings, D.M., Guelfi, S., Liu, W., Solim, M.A.N., Moens, T.G., Paublete, R.M., Ali, S.S., Perona, M., Desai, R., Smith, K.J., Latcham, J., Fulleylove, M., Richardson, J.C., Hardy, J., Edwards, F.A., 2015. A Genome-wide Gene-Expression Analysis and Database in Transgenic Mice during Development of Amyloid or Tau Pathology. CellReports 10, 633644. doi:10.1016/j.celrep.2014.12.041

McClatchy, D.B., Dong, M.-Q., Wu, C.C., Venable, J.D., Yates, J.R., 2007. 15N Metabolic Labeling of Mammalian Tissue with Slow Protein Turnover. J. Proteome Res. 6, 2005-2010. doi:10.1021/pr060599n

Moreno, J.A., Radford, H., Peretti, D., Steinert, J.R., Verity, N., Martin, M.G., Halliday, M., Morgan, J., Dinsdale, D., Ortori, C.A., Barrett, D.A., Tsaytler, P., Bertolotti, A., Willis, A.E., Bushell, M., Mallucci, G.R., 2012. nature11058. Nature 485, 507-511. doi:10.1038/nature11058

Musiek, E.S., Holtzman, D.M., 2015. Three dimensions of the amyloid hypothesis: time, space and "wingmen." Nature neuroscience 18, 800-806. doi:10.1038/nn.4018

Narayan, V., Ly, T., Pourkarimi, E., Murillo, A.B., Gartner, A., Lamond, A.I., Kenyon, C., 2016. Deep Proteome Analysis Identifies Age-Related Processes in C.\&nbsp;elegans. Cell Systems 3, 144-159. doi:10.1016/j.cels.2016.06.011

Ohsumi, Y., 2006. Protein turnover. IUBMB Life (International Union of Biochemistry and Molecular Biology: Life) 58, 363-369. doi:10.1080/15216540600758539

Olzscha, H., Schermann, S.M., Woerner, A.C., Pinkert, S., Hecht, M.H., Tartaglia, G.G., Vendruscolo, M., Hayer-Hartl, M., Hartl, F.U., Vabulas, R.M., 2011. Amyloid-like Aggregates Sequester Numerous Metastable Proteins with Essential Cellular Functions. Cell 144, 67-78. doi:10.1016/j.cell.2010.11.050

Potter, R., Patterson, B.W., Elbert, D.L., Ovod, V., Kasten, T., Sigurdson, W., Mawuenyega, K., Blazey, T., Goate, A., Chott, R., Yarasheski, K.E., Holtzman, D.M., Morris, J.C., Benzinger, T.L.S., Bateman, R.J., 2013. Increased in vivo amyloid- $\beta 42$ production, exchange, and loss in presenilin mutation carriers. Sci Transl Med 5, 189ra77-189ra77. doi:10.1126/scitranslmed.3005615

Price, J.C., Guan, S., Burlingame, A., 2010a. Analysis of proteome dynamics in the mouse brain, in:. Presented at the Proceedings of the .... doi:10.1073/pnas.1401578111

Price, J.C., Guan, S., Burlingame, A., Prusiner, S.B., Ghaemmaghami, S., 2010b. Analysis of proteome dynamics in the mouse brain. Proceedings of the 
National Academy of Sciences 107, 14508-14513. doi:10.1073/pnas.1006551107

Saito, T., Matsuba, Y., Mihira, N., Takano, J., Nilsson, P., Itohara, S., Iwata, N., Saido, T.C., 2014. Single App knock-in mouse models of Alzheimer's disease. Nature neuroscience 17, 661-663. doi:10.1038/nn.3697

Savas, J.N., Toyama, B.H., Xu, T., Yates, J.R., Hetzer, M.W., 2012. Extremely Long-Lived Nuclear Pore Proteins in the Rat Brain. Science 335, 942-942. doi:10.1126/science.1217421

Savas, J.N., Wang, Y.-Z., DeNardo, L.A., Martínez-Bartolomé, S., McClatchy, D.B., Hark, T.J., Shanks, N.F., Cozzolino, K.A., Lavallée-Adam, M., Smukowski, S.N., Park, S.K., Kelly, J.W., Koo, E.H., Nakagawa, T., Masliah, E., Ghosh, A., Yates lii, J.R., 2017. Amyloid Accumulation Drives Proteomewide Alterations in Mouse Models of Alzheimer's Disease- like Pathology. CellReports 21, 2614-2627. doi:10.1016/j.celrep.2017.11.009

Savitski, M.M., Zinn, N., Faelth-Savitski, M., Poeckel, D., Gade, S., Becher, I., Muelbaier, M., Wagner, A.J., Strohmer, K., Werner, T., Melchert, S., Petretich, M., Rutkowska, A., Vappiani, J., Franken, H., Steidel, M., Sweetman, G.M., Gilan, O., Lam, E.Y.N., Dawson, M.A., Prinjha, R.K., Grandi, P., Bergamini, G., Bantscheff, M., 2018. Multiplexed Proteome Dynamics Profiling Reveals Mechanisms Controlling Protein Homeostasis. Cell 173, 260-274.e25. doi:10.1016/j.cell.2018.02.030

Schmidt, E.K., Clavarino, G., Ceppi, M., Pierre, P., 2009. SUnSET, a nonradioactive method to monitor protein synthesis. Nature Methods 6, 275277. doi:10.1038/nmeth.1314

Schwanhäusser, B., Busse, D., Li, N., Dittmar, G., Schuchhardt, J., Wolf, J., Chen, W., Selbach, M., 2011. Global quantification of mammalian gene expression control. Nature 473, 337-342. doi:10.1038/nature10098

Shen, W., Liu, H.-H., Schiapparelli, L., McClatchy, D., He, H.-Y., Yates lii, J.R., Cline, H.T., 2014. Acute Synthesis of CPEB Is Required for Plasticity of Visual Avoidance Behavior in Xenopus. CellReports 6, 737-747. doi:10.1016/j.celrep.2014.01.024

Szklarczyk, D., Morris, J.H., Cook, H., Kuhn, M., Wyder, S., Simonovic, M., Santos, A., Doncheva, N.T., Roth, A., Bork, P., Jensen, L.J., Mering, von, C., 2017. The STRING database in 2017: quality-controlled protein-protein association networks, made broadly accessible. Nucleic Acids Research 45, D362-D368. doi:10.1093/nar/gkw937

Toyama, B.H., Savas, J.N., Park, S.K., Harris, M.S., Ingolia, N.T., Yates lii, J.R., Hetzer, M.W., 2013. Identification of Long-Lived Proteins Reveals Exceptional Stability of Essential Cellular Structures. Cell 154, 971-982. doi:10.1016/j.cell.2013.07.037

Vilchez, D., Saez, I., Dillin, A., 2014. The role of protein clearance mechanisms in organismal ageing and age-related diseases. Nature Communications 5, 1-13. doi:10.1038/ncomms6659

Walther, D.M., Kasturi, P., Zheng, M., Pinkert, S., Vecchi, G., Ciryam, P., Morimoto, R.I., Dobson, C.M., Vendruscolo, M., Mann, M., Hartl, F.U., 2015. Widespread Proteome Remodeling and Aggregation in Aging C.\&nbsp;elegans. Cell 161, 919-932. doi:10.1016/j.cell.2015.03.032 
Walther, D.M., Mann, M., 2011. Accurate Quantification of More Than 4000 Mouse Tissue Proteins Reveals Minimal Proteome Changes During Aging. Mol Cell Proteomics 10, M110.004523-M110.004523. doi:10.1074/mcp.M110.004523 Woerner, A.C., Frottin, F., Hornburg, D., Feng, L.R., Meissner, F., Patra, M., Tatzelt, J., Mann, M., Winklhofer, K.F., Hartl, F.U., Hipp, M.S., 2016.

Cytoplasmic protein aggregates interfere with nucleocytoplasmic transport of protein and RNA. Science 351, 173-176. doi:10.1126/science.aad2033

Yancopoulou, D., Spillantini, M.G., 2003. Tau protein in familial and sporadic diseases. Neuromol Med 4, 37-48. doi:10.1385/NMM:4:1-2:37

Ye, L., Fritschi, S.K., Schelle, J., Obermüller, U., Degenhardt, K., Kaeser, S.A., Eisele, Y.S., Walker, L.C., Baumann, F., Staufenbiel, M., Jucker, M., 2015. Persistence of A $\beta$ seeds in APP null mouse brain. Nature neuroscience 18, 1559-1561. doi:10.1038/nn.4117

Zetterberg, H., Mattsson, N., 2014. Understanding the cause of sporadic Alzheimer's disease. Expert Review of Neurotherapeutics 14, 000-000. doi:10.1586/14737175.2014.915740 


\section{Figure 1.}

\section{A}

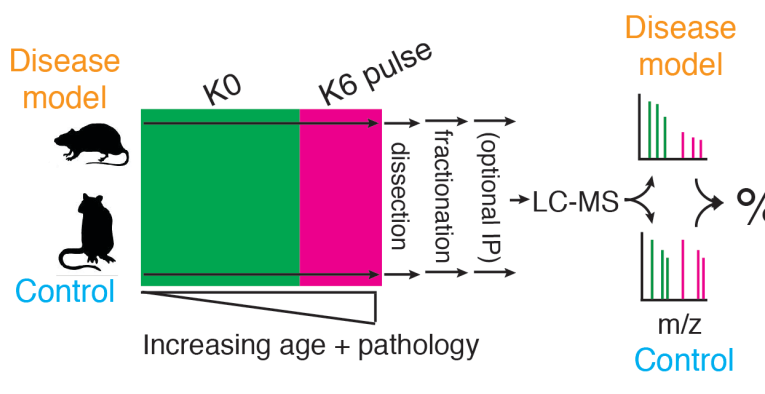

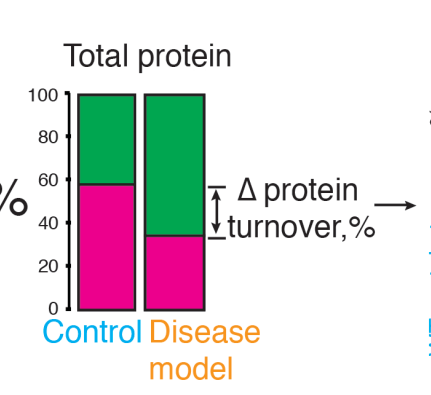

C Hippocampus

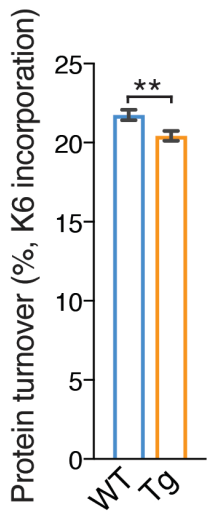

D

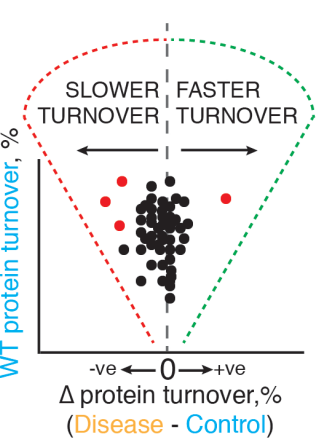

E
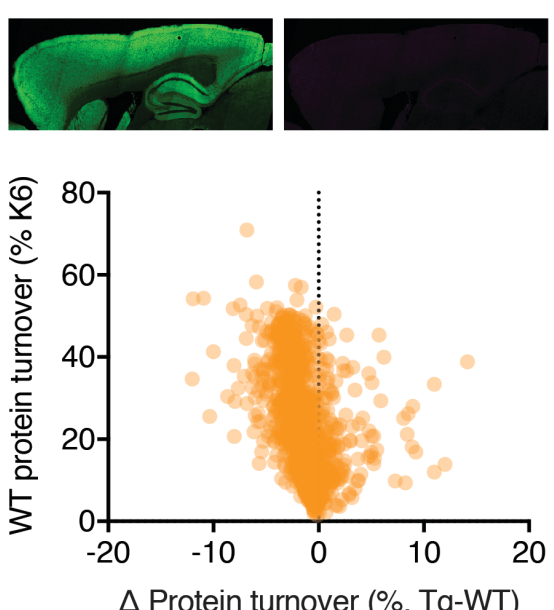

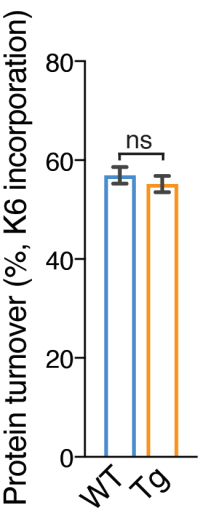

Liver

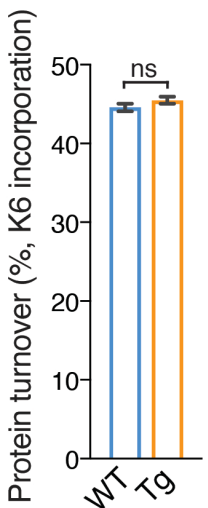


Figure 1. Metabolic labelling of live mice to measure changes in protein turnover.

A, left, Schematic summarising the ${ }^{13} \mathrm{C}$ heavy lysine (K6) labelling method for measuring changes in protein turnover in mice. Cohorts of genetically and age matched mice were maintained on regular food until the desired labelling window. The groups of mice are then switched to $\mathrm{K} 6$ diet for an identical period before tissues were processed for orbitrap LC-MS/MS.

Middle, lon pairs with a $6 \mathrm{Da}$ difference in mass were detected and sequenced, corresponding to peptides with and without $\mathrm{K} 6$. The relative incorporation of $\mathrm{K} 6$ was calculated in disease and wildtype mice.

Right, The mean difference in K6 incorporation is calculated for each protein and plotted ( $x$-axis) to highlight slowdown or increases in protein turnover versus whether a protein has fast or slow turnover (WT K6 incorporation, $y$-axis).

B, Top, Immunohistochemical detection of synaptic marker, left, Psd95 and right, $\beta$-amyloid pathology in sagittal sections of pre-symptomatic TgCRND8 (P113) mouse brain.

Bottom, Scatter plot showing protein turnover changes in the hippocampus of presymptomatic (P113) TgCRND8 mice (see Table S1). 1392 proteins were quantified in both diseased and healthy cohorts of mice (2 of 3 mice). The mean difference of K6 incorporation for each protein ( $x$-axis, $\mathrm{Tg}-\mathrm{WT}$ ) was plotted against the incorporation in WT (y-axis). 3 TgCRND8 and 3 age-, sex-, and background matched WT mice were K6 labelled for 6 days. These data indicate a global decrease in protein turnover for hippocampal proteins with both a slow and fast turnover.

C Bar chart showing average protein turnover of 1392 proteins in the hippocampus of TgCRND8 and WT mice. An overall 6.1\% slowdown in turnover was recorded in the hippocampus $(P=0.0037)$. Error bars indicate SEM. ${ }^{* *} P<0.01$. 
D, Bar chart showing average plasma protein turnover in TgCRND8 and WT mice. No significant difference was detected $(P=0.128, \mathrm{n}=118)$. Error bars indicate SEM. ns, not significant.

E, Bar chart showing average liver protein turnover in TgCRND8 and WT mice. No significant difference was detected $(P=0.17, \mathrm{n}=590)$. ns, not significant. 


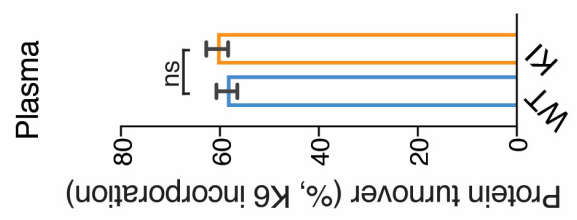

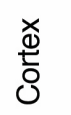

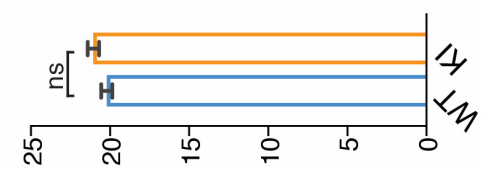

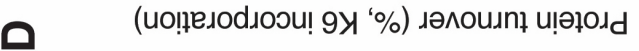

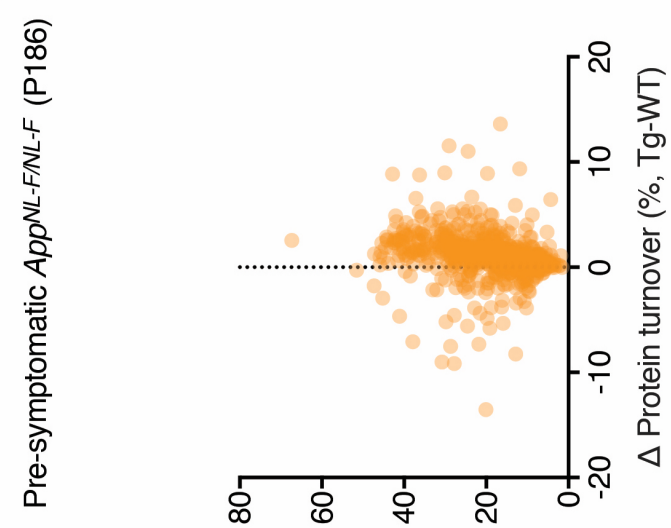

0

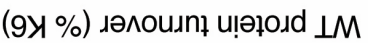
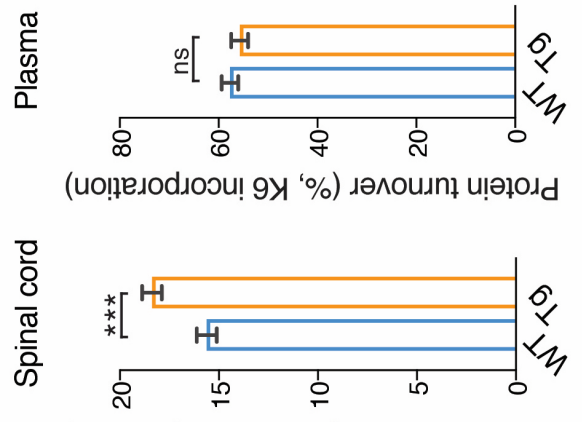

I

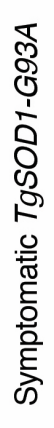

U

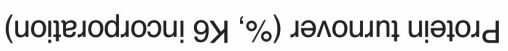

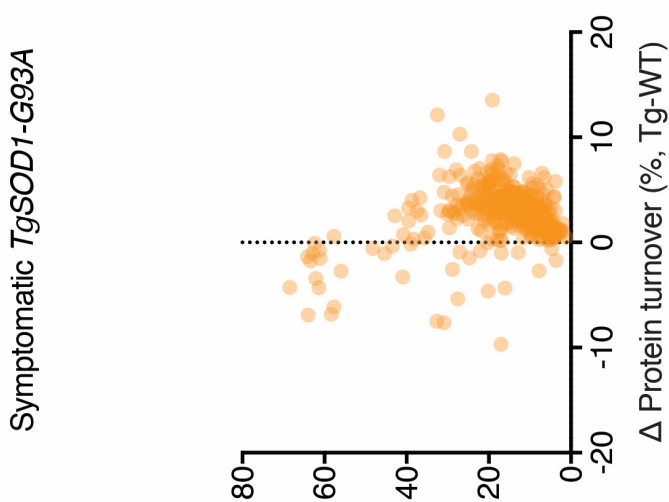

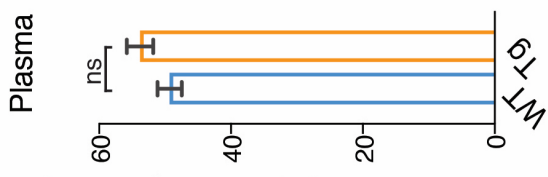

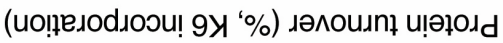
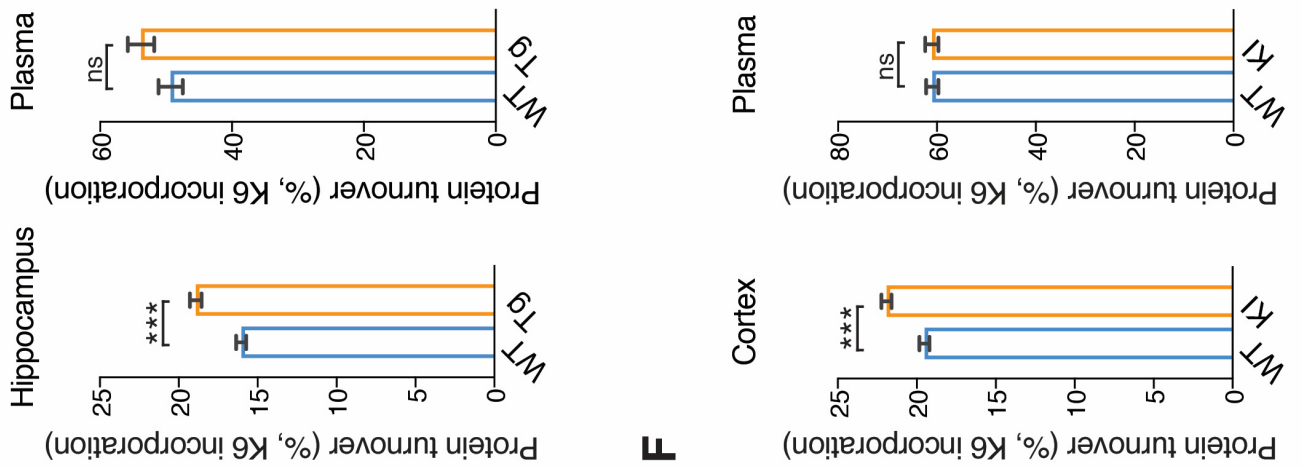

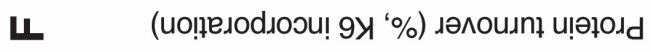

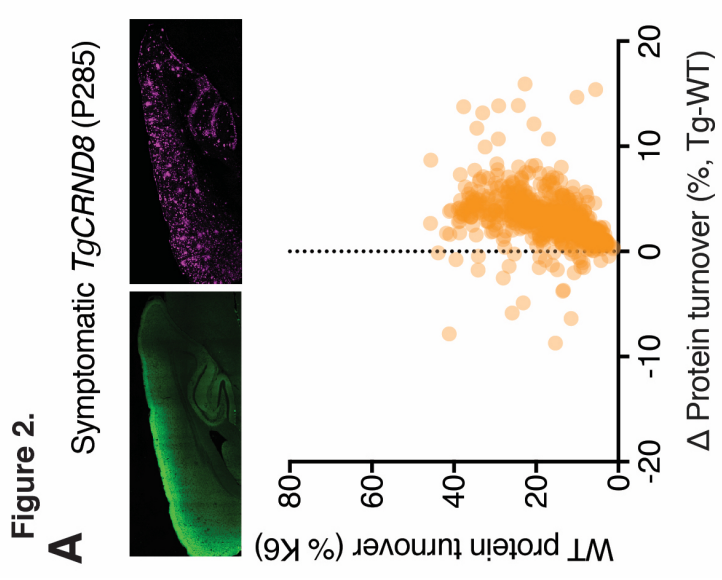

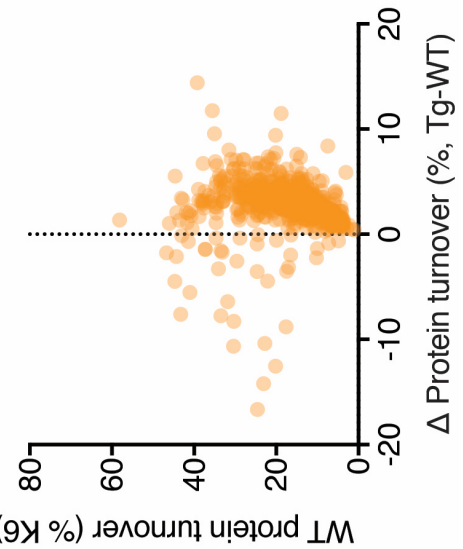


Figure 2. Differences in protein turnover in transgenic and knock-in models of $A D$, and a transgenic model of ALS.

A, Top, Immunohistochemical detection of synaptic marker, left, Psd95 and right, $\beta$-amyloid pathology in sagittal sections of symptomatic TgCRND8 (P285) mouse brain.

Bottom, Scatter plot showing protein turnover changes in the hippocampus of symptomatic (P285) TgCRND8 mice (see Table S1). 847 proteins were quantified, and the difference in turnover characteristics between proteins in diseased and healthy animals were plotted as described in Figure 1B.

B, Left Bar chart showing the average hippocampal protein turnover of 847 proteins in TgCRND8 and WT mice. An overall 18.0\% increase in protein turnover was detected $(P<0.0001)$. Error bars indicate SEM. ${ }^{* * *} P<0.0001$.

Right Bar chart showing average plasma protein turnover in TgCRND8 and WT mice. No significant difference was detected $(P=0.102, \mathrm{n}=74)$. Error bars indicate SEM. ns, not significant.

C, Scatter plot showing protein turnover changes in the cortex of pre-symptomatic (P186) App ${ }^{N L-F / N L-F}$ mice (see Table S1). 721 proteins were quantified, and the difference in turnover characteristics between proteins in diseased and healthy animals were plotted as described in Figure 1B.

D, Left Bar chart showing the average cortex protein turnover of 721 proteins in $A p p^{N L-F / N L-F}$ and WT mice. No change in protein turnover was detected $(P<$ 0.0735). Error bars indicate SEM. ns, not significant.

Right Bar chart showing average plasma protein turnover in App ${ }^{N L-F / N L-F}$ and WT mice. No significant difference was detected $(P=0.534, \mathrm{n}=48)$. Error bars indicate SEM. ns, not significant. 
E, Top, Immunohistochemical detection of synaptic marker, left, Psd95 and right, $\beta$-amyloid pathology in sagittal sections of symptomatic App ${ }^{N L-F / N L-F}$ (P500) mouse brain.

Bottom, Scatter plot showing protein turnover changes in the cortex of

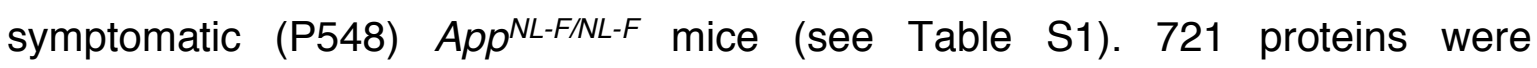
quantified, and the difference in turnover characteristics between proteins in diseased and healthy animals were plotted as described in Figure 1B.

F, Left Bar chart showing the average cortex protein turnover of 847 proteins in $A p p^{N L-F / N L-F}$ and WT mice. An overall $15.7 \%$ increase in protein turnover was detected $(P<0.0001)$. Error bars indicate SEM. ${ }^{* * *} P<0.0001$.

Right Bar chart showing average plasma protein turnover in App $p^{N L-F / N L-F}$ and WT mice. No significant difference was detected $(P=0.961, \mathrm{n}=95)$. Error bars indicate SEM. ns, not significant.

G, Scatter plot showing protein turnover changes in the spinal cord of acutely symptomatic (P120) TgSOD1-G93A mice (see Table S1). 496 proteins were quantified, and the difference in turnover characteristics between proteins in diseased and healthy animals were plotted as described in Figure 1B.

H, Left Bar chart showing the average protein turnover of 496 proteins in the spinal cord of TgSOD1-G93A and WT mice. An overall 17.6\% increase in protein turnover was detected $(P<0.0001)$. Error bars indicate SEM. ${ }^{\star \star *} P<0.0001$.

Right Bar chart showing average plasma protein turnover in TgSOD1-G93A and WT mice. No significant difference was detected $(P=0.417, \mathrm{n}=89)$. Error bars indicate SEM. ns, not significant. 

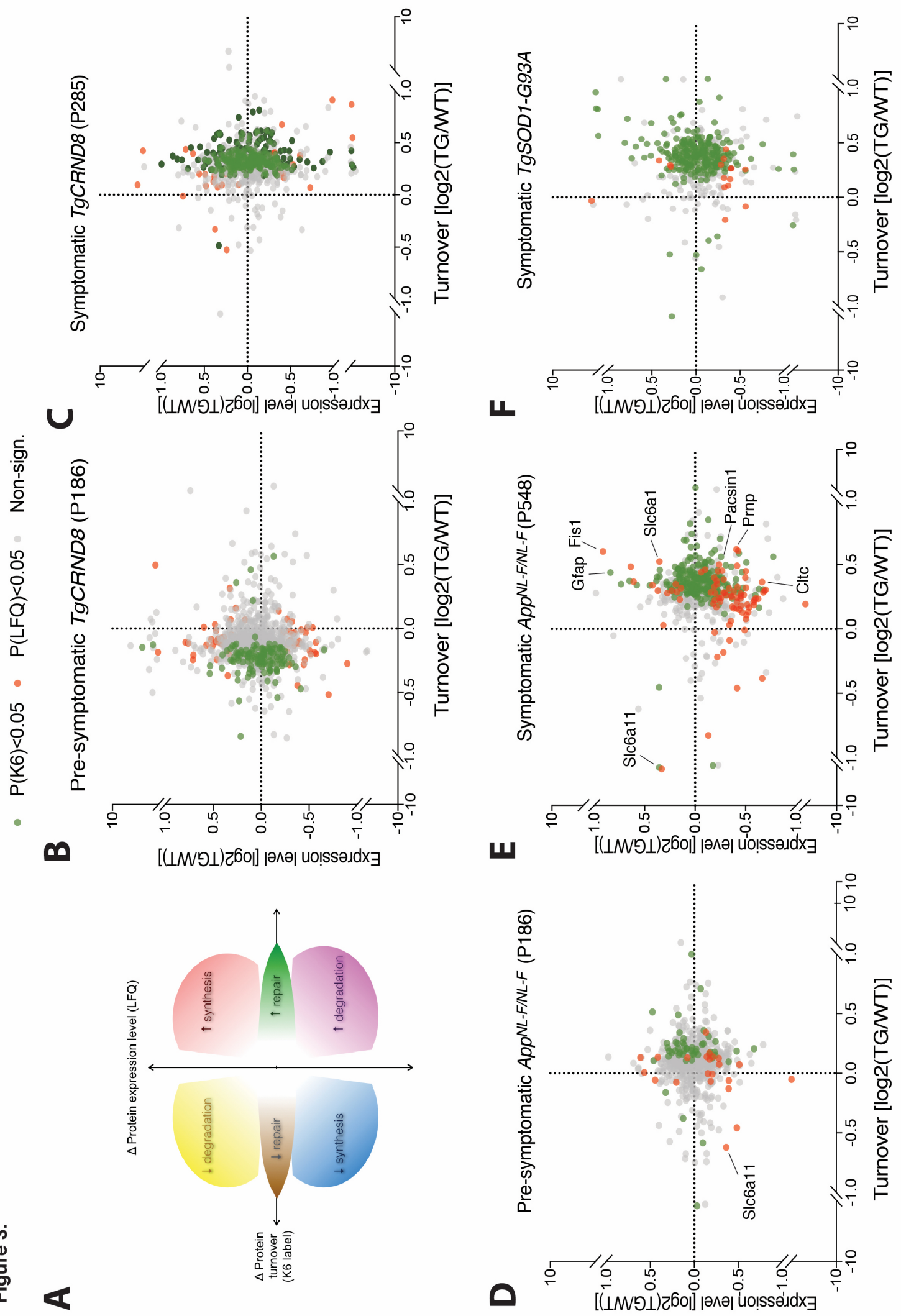
Figure 3. Multidimensional measurement of proteome dynamics in live mice.

A, Schematic of a dynaplot showing the change in protein turnover ( $x$-axis, K6 label) plotted against the change in steady state expression level ( $y$-axis, LFQ). The coordinate space of the plot reflect dynamics of a protein that can be attributed to a net increase (red) or decrease (blue) in the rate of synthesis; net increase (magenta) or decrease (yellow) in degradation. Change in turnover that does not result in a change in steady state expression indicate change in flux of increasing (green) or decreasing repair (brown).

B, Dynaplot of hippocampal proteins in pre-symptomatic (P113) TgCRND8 mice, as compared to healthy, matched control mice. Proteins that were significantly different in turnover $(P<0.01)$ are highlighted in green, while those that were significantly different in steady state amount $(P<0.01)$ are highlighted in red.

C, Dynaplot of hippocampal proteins in acutely symptomatic (P285) TgCRND8 mice, as compared to healthy, matched control mice. 4.

D, Dynaplot of cortex proteins in pre-symptomatic (P186) App $p^{N L-F / N L-F}$ mice, as compared to healthy, matched control mice.

E, Dynaplot of cortex proteins in symptomatic (P548) App ${ }^{N L-F / N L-F}$ mice, as compared to healthy, matched control mice.

F, Dynaplot of hippocampal proteins in acutely symptomatic (P120) TgSOD1G93A mice, as compared to healthy, matched control mice. See Table S 4. 
bioRxiv preprint doi: https://doi.org/10.1101/472118; this version posted November 17, 2018. The copyright holder for this preprint (which was not certified by peer review) is the author/funder. All rights reserved. No reuse allowed without permission.

Figure 4.

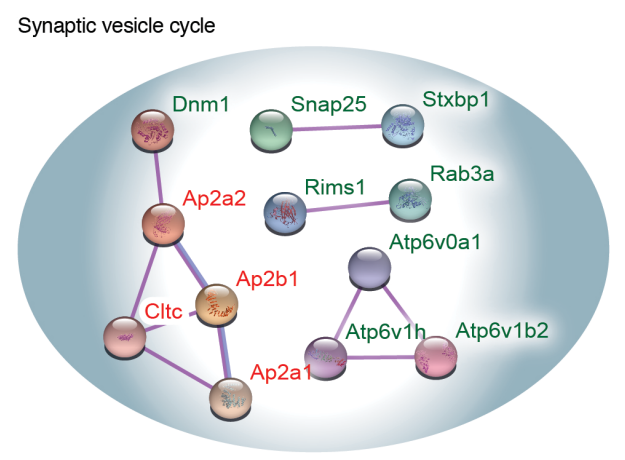

Mitochondria (oxidative phosphorylation, citrate cycle)

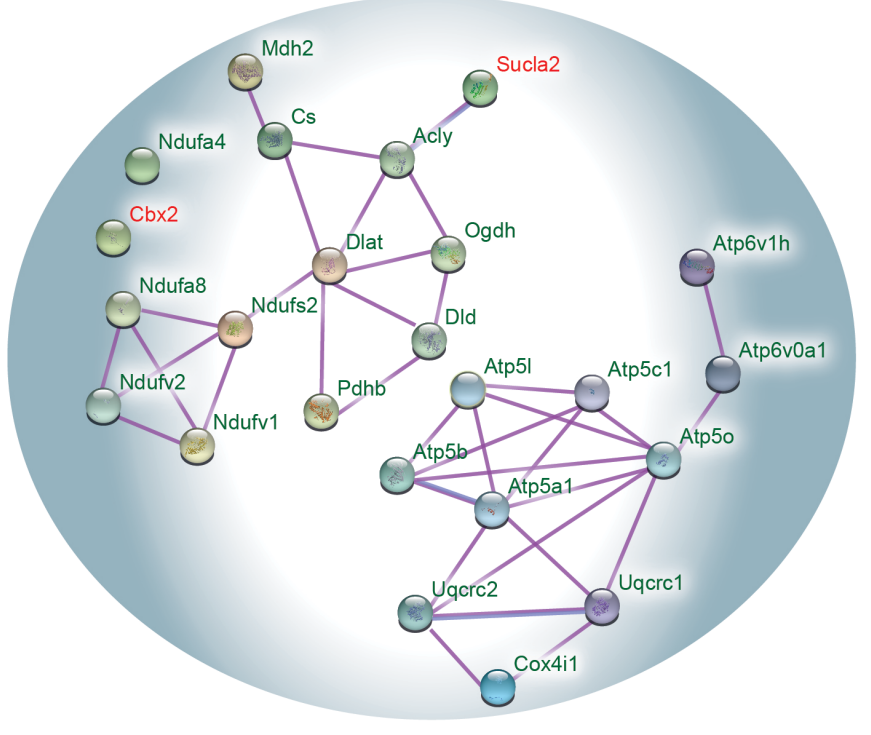


Figure 4 Proteins with perturbed dynamics converge on presynaptic functions in mouse model of Alzheimer's disease.

Gene ontology enrichment using KEGG database (see methods) identified left, synaptic vesicle recycling, and right, mitochondrial pathways enriched with the proteins whose turnover (green) or steady state amount (red) have significantly changed in symptomatic (P548) App NL-F/NL-F cortex. Purple and blue edges, indicate empirically determined protein-protein interactions, and protein homology, respectively. 


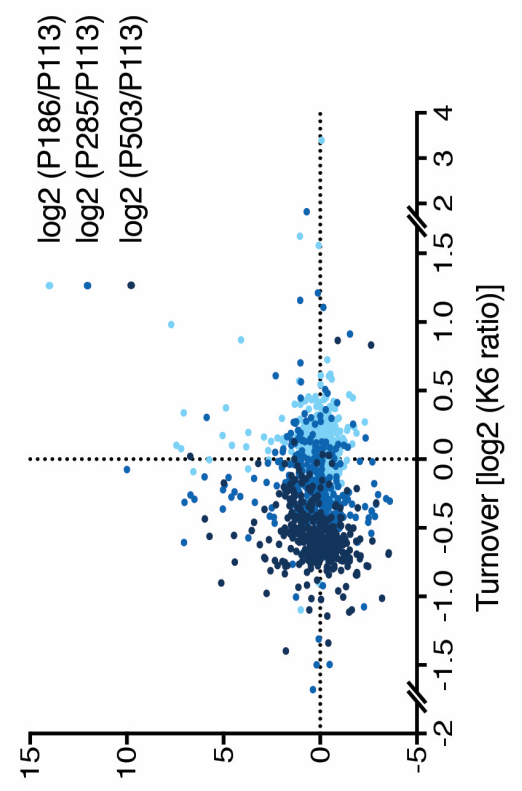

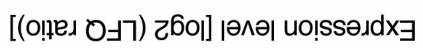

\section{$\cup$}
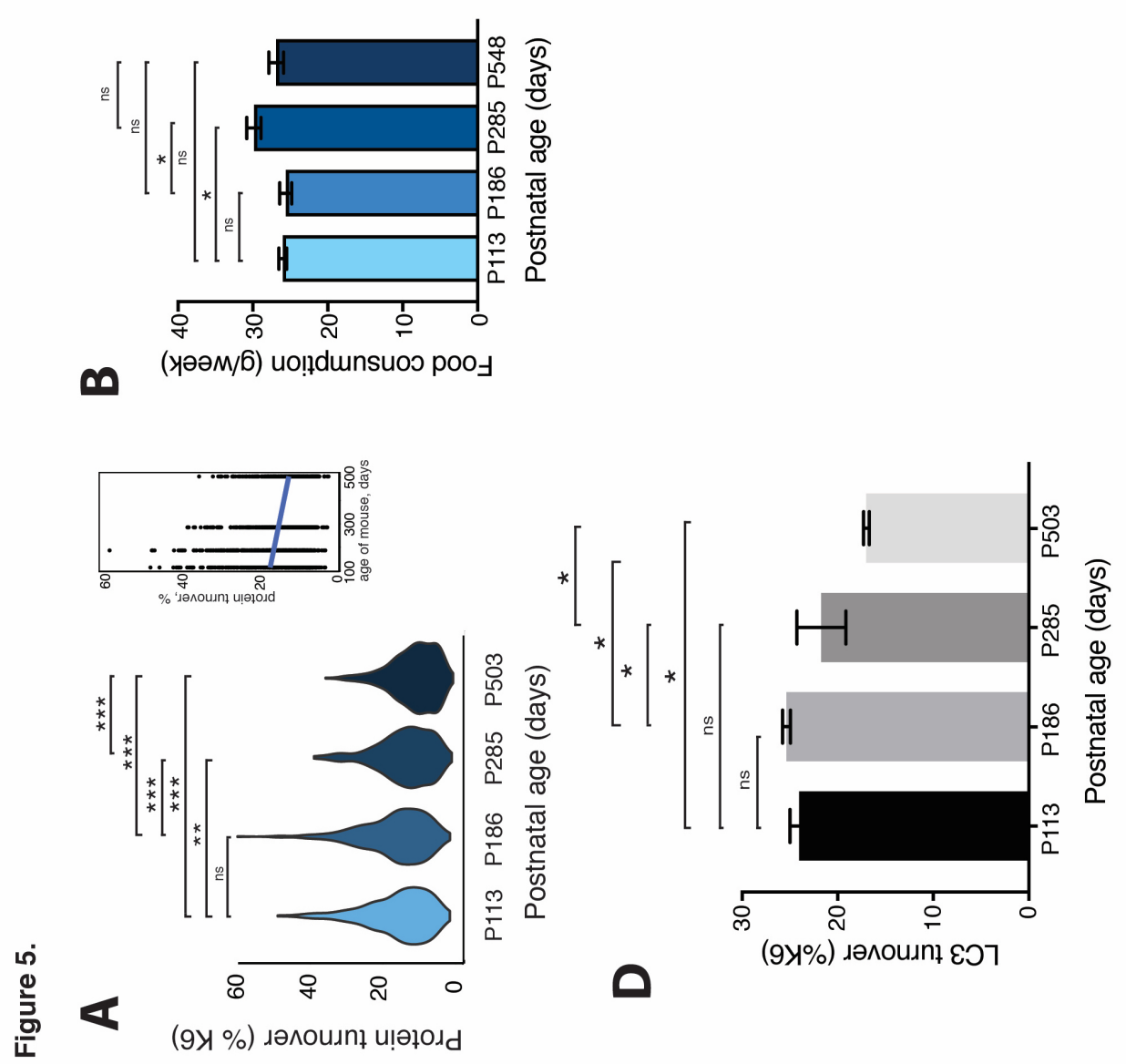
Figure 5. Proteome dynamics associated with ageing in healthy mice.

A, Average protein turnover in healthy mouse cortex at various ages. Total number of proteins used to compare turnover across all ages $=360$. $P$ values for the comparisons (descending from top) $=1.063 \mathrm{E}-06,4.557 \mathrm{E}-14,1.220 \mathrm{E}-05$, 6.799E-14, 0.003, 0.175 .

B, Average food consumption of mice at different ages: P113 ( $n=4)$, P186 ( $n=2)$, P285 ( $n=4)$, P548 $(n=11)$. No significant change in appetite associated with ageing was detected. $P$ values for the comparisons (descending from top) $=0.127$, $0.675,0.047,0.694,0.011,0.692$.

C, Dynaplot of mouse cortex proteins depicting the change in proteome dynamics in healthy control mice from P113 to P186 (sky blue), to P285 (blue), and to P548 (dark blue). These data are expressed ratiometrically to allow simpler visualisation between different ages of mice.

D, Bar graph showing apparent decrease in turnover of LC3, marker of autophagy, as mice age. Turnover was estimated by percentage heavy lysine incorporation (P6) in mice at postnatal days 113, 186, 285 and 503. ${ }^{*} P<0.05$. n.s., nonsignificant. 